American Journal of Applied Sciences 4 (2): 80-84, 2007

ISSN 1546-9239

(C) 2007 Science Publications

\title{
High Saturation Induction for Bi-Substituted Yttrium Iron Garnet Prepared Via Sol Gel Technique
}

\author{
Noorhana Yahya and Goh Kah Hean \\ Advanced Materials Laboratory, Institute of Advanced Technology, Universiti Putra Malaysia \\ 43400 UPM Serdang, Malaysia \\ Department of Physics, Faculty of Science, Universiti Putra Malaysia, 43400 UPM Serdang, Malaysia
}

\begin{abstract}
Y}_{3.0-\mathrm{x}} \mathrm{Bi}_{\mathrm{x}} \mathrm{Fe}_{5} \mathrm{O}_{12}$ samples $(\mathrm{x}=0.2$ and 0.4$)$ were prepared via novel sol-gel and conventional solid-state techniques. The effect of bismuth in both techniques was investigated in terms of shrinkage, density, hysteresis and initial permeability. Sharp and clear diffraction XRD lines with highest peak appear at about $32^{\circ}$ of the $2 \theta$, for all the powders sintered at $900^{\circ} \mathrm{C}$ and $1250^{\circ} \mathrm{C}$ for both techniques. In evaluating the magnetic properties, it was observed that the saturation induction $(1.1902 \mathrm{kG})$ of sample prepared via sol-gel technique $\left(\mathrm{Y}_{2.8} \mathrm{Bi}_{0.2} \mathrm{Fe}_{5} \mathrm{O}_{12}\right)$ is more than $200 \%$ higher than sample with the same formula prepared via conventional technique. Fine grained microstructure with average grain size of about $5 \mu \mathrm{m}$ and higher shrinkage, about $11 \%$ were observed from the samples prepared via sol gel technique. It is concluded that samples prepared via sol gel technique appear to be an attractive route due to the possible reduction of cost of production and the enhanced magnetic and structural properties of the sample.
\end{abstract}

Key words: Conventional solid state, hysteresis, initial permeability, sol gel technique, C (conventional) S (sol-gel)

\section{INTRODUCTION}

Ferrites may be defined as magnetic materials composed of oxide containing ferric ions as the main constituent. The term is often restricted to such materials having mineral spinel cubic crystal structure, but it is also loosely applied to magnetic oxides in general irrespective of their crystallic structure. Yttrium iron garnet (YIG) has been studied intensively by researchers for decades now. It prides itself as being one of the most well known soft ferrites hitherto. Its grandeur can be justified by its application in microwave devices such as spatial light modulators, guided wave optical isolators ${ }^{[1]}$, optical Faraday rotator $^{[2]}$, phase shifters, switches and sensors ${ }^{[3,4]}$. Doped YIG were also subjected to scrutiny. The magnetic and electric properties of these YIG compounds changed slightly or drastically based on the type and quantity of dopant as well as substituent employed. Recent studies involved the work of Marysko ${ }^{[5]}$, who studied the properties of cobalt doped YIG films and the work of Xhang et al. that focused on the magneto-optical properties of $\mathrm{Nd}$ substituted $\mathrm{YIG}^{[6]}$. This work however deals with preparation of $\mathrm{Bi}$ $\mathrm{Y}_{3} \mathrm{Fe}_{5} \mathrm{O}_{12}$ samples using conventional, solid-state and novel, sol-gel techniques. The magnetic and structural properties of all the samples were investigated and compared.

\section{MATERIALS AND METHODS}

The raw materials used for the conventional technique in this project are bismuth oxide (purity: 99.98\%), yttrium oxide (purity: 99.9\%) and iron oxide (purity: 99.99\%). For conventional technique, raw materials were wet mixed in milling machine for 16 hours to get a homogeneous mixture and subsequently, filtering, drying and pre-sintering were done at $1150^{\circ} \mathrm{C}$ in air. On the other hand, stoichiometric mixtures of nitrates, comprise of iron (III) nitrate, $\mathrm{Fe}\left(\mathrm{NO}_{3}\right)_{3} .9 \mathrm{H}_{2} \mathrm{O}$, bismuth (III) nitrate, $\mathrm{Bi}\left(\mathrm{NO}_{3}\right)_{3} \cdot 9 \mathrm{H}_{2} \mathrm{O}$ and yttrium nitrate, $\mathrm{Y}\left(\mathrm{NO}_{3}\right)_{3} \cdot 6 \mathrm{H}_{2} \mathrm{O}$ were weight and dissolve in an aqueous solution of citric acid for the sol-gel technique. The nitrates were dissolved by stirring them with a magnetic stirrer at 300 r.p.m at room temperature for three days. The solution was then heated up to $80^{\circ} \mathrm{C}$ with the same stirring rate until the gel was obtained. The gel was then dried at $110^{\circ} \mathrm{C}$ in an oven for another 24 hours. The dried powders were then sent for x-ray diffraction measurements to discern the reaction pathway and to study the gel to crystalline transformation. The samples were then pre-sintered at $1150^{\circ} \mathrm{C}$ (solid-state) and $800^{\circ} \mathrm{C}$ (sol-gel) in air for 5 hours. All the pre-sintered green powders were wet crushed for 6 hours using Planetary Micromill to obtain fine particles granules. The green powders were moulded to a toroidal shape using hydraulic machine at $60 \mathrm{kN}$. $1.5 \%$ of PVA acted as binder and $1.5 \%$ of zinc

Corresponding Author: $\quad$ Noorhana Yahya, Advanced Materials Laboratory, Institute of Advanced Technology, Universiti Putra Malaysia, 43400 UPM Serdang, Malaysia 
stearate acted as lubricant were added into the powders. All the toroids were then sintered at $1250^{\circ} \mathrm{C}$ for 10 hours and $900^{\circ} \mathrm{C}$ for 5 hours in air, for the conventional and novel techniques, respectively. Samples that were prepared via solid state technique are denoted as $\mathrm{C} 1$ $\left(\mathrm{Y}_{2.8} \mathrm{Bi}_{0.2} \mathrm{Fe}_{5} \mathrm{O}_{12}\right)$ and $\mathrm{C} 2\left(\mathrm{Y}_{2.6} \mathrm{Bi}_{0.4} \mathrm{Fe}_{5} \mathrm{O}_{12}\right)$. On the other hand, samples that were prepared via sol gel technique are denoted as $\mathrm{S} 1 \quad\left(\mathrm{Y}_{2.8} \mathrm{Bi}_{0.2} \mathrm{Fe}_{5} \mathrm{O}_{12}\right)$ and $\mathrm{S} 2$ $\left(\mathrm{Y}_{2.6} \mathrm{Bi}_{0.4} \mathrm{Fe}_{5} \mathrm{O}_{12}\right)$. For the hysteresis measurements (AMH-Hysteresis Graph, Walker Scientific), the samples were wounded 20 turns of $0.3 \mathrm{~mm}$ diameter insulating copper wire as its primary turns and 40 turns as the secondary turns. All the four ends of the copper wire were scraped with grade 1000 sand paper and were then soldered with silver to ensure contact during measurements. Value of coercive force $\left(\mathrm{H}_{\mathrm{c}}\right)$, remanence $\left(\mathrm{B}_{\mathrm{r}}\right)$, saturation induction $\left(B_{\max }\right)$ and core loss $\left(\mathrm{W}_{\mathrm{h}}\right)$ can be obtained from this measurements. To obtain these values, the effective area, A and path length, $\mathrm{P}$ of the toroidal sample had to be calculated from the formulae below:

Effective area,

$$
\mathrm{A}=\frac{(\mathrm{Do}-\mathrm{Di}) \mathrm{t}}{2}
$$

Path length,

$$
\mathrm{P}=\frac{(\mathrm{Do}+\mathrm{Di}) \pi}{2}
$$

Inductance $\left(\mathrm{L}_{\mathrm{S}}\right)$ measurements were essential as values of the initial permeability had to be obtained by this measurement. The samples were connected to a Hewlett Packard model 4195A Network/spectrum analyzer. Series inductance values, Ls, were taken from $1 \mathrm{MGz}$ to $50 \mathrm{MHz}$. Initial permeability values can be obtained automatically from the analyzer.

\section{RESULTS AND DISCUSSION}

Figure 1 shows the XRD patterns of the $\mathrm{Bi}$ substitute YIG particles for samples $\mathrm{C} 1$ and $\mathrm{S} 1$ after pre-sintering and sintering. A clear diffraction line with highest peak appears at about $32^{\circ}$ of the $2 \theta$, for all the powders. Sharp and clear diffraction lines could be observed for all the powders sintered at $900^{\circ} \mathrm{C}$ and $1250^{\circ} \mathrm{C}$ for both the techniques.

Interesting however is the disappearance of the unknown peak mentioned above for $\mathrm{C} 1$ after sintering process was done. This corresponded to the progression of crystal growth of the entire particles.

The density of sample would increase with the increase of $\mathrm{Bi}^{3+}$ ions concentration. It is because $\mathrm{Bi}^{3+}$ ion is placed in group 5 in the periodic table, with the atomic weight of 208.98 a.m.u (atomic mass unit) comparing to $\mathrm{Y}^{3+}$ ion with atomic weight of just 88.91 a.m.u. Referring to Table 1 , the increase of $\mathrm{Bi}^{3+}$ ions concentration has increased the total atomic weight of the sample and as a result the density increases ${ }^{[8]}$.
However, the density of samples prepared via solgel technique is greater than those prepared via conventional technique. Samples prepared via sol-gel technique are speculated to have finer grains and therefore would have higher density. The difference in density is due to the mixing of solution in atomic molecular form, which resulted in large surface area.

The shrinkage during firing depends on the reactivity of the milled powder, the binder content and the firing conditions (temperature, time and atmosphere). Improper preparation may result in extensive shrinkage and as a result micro-cracks could occur. Linear shrinkage during firing may vary from $10-20 \%{ }^{[9]}$. In this experiment, the shrinkage is less then $12 \%$ for all the samples. It could also be observed that the shrinkage increases with the increase $\mathrm{Bi}^{3+}$ concentration for both the techniques. The melting point of bismuth oxide is $825^{\circ} \mathrm{C}^{[8]}$. Since the samples were sintered at high temperature $\left(900^{\circ} \mathrm{C}\right.$ and $1250^{\circ} \mathrm{C}$ via both techniques), we anticipate the bismuth oxide to be in liquid form. During sintering process we speculate that $\mathrm{Bi}_{2} \mathrm{O}_{3}$ may soften to liquid phase providing attractive capillary forces for neighbouring particles to come closer and react.

This process, commonly known as liquid phase sintering ${ }^{[9]}$, causes the enhancement of reactivity of the powder to form the garnet phase when the $\mathrm{Bi}^{3+}$ ions concentration was increase. In consequence, the shrinkage will also increase. We observed fine grained and traces of some melting regions (Fig. 4). Larger grain size (Fig. 3) for the S1 sample, with almost poreless microstructure, prepared via sol gel were observed even though we speculated them to be in nano size and smaller than those prepared via sol gel technique $^{[7]}$. However, for the sol gel technique, since the starting materials are nitrates that dissolve in citric acids, we anticipate the melting point to be much lower. The reactivity during sintering is enhanced and as such the $900^{\circ} \mathrm{C}$ is found to be too high that causes the grains to grow much more than we expected, approximately $14 \mu \mathrm{m}$. The shrinkage of samples prepared via sol-gel technique was greater than those prepared via conventional technique (Table 1).

Observing Fig 2, the saturation induction, $\mathrm{B}_{\max }$, for samples prepared via sol gel technique are higher then those prepared via conventional technique. The $\mathrm{B}_{\max }$ for $\mathrm{Y}_{2.8} \mathrm{Bi}_{0.2} \mathrm{Fe}_{5} \mathrm{O}_{12}$ sample prepared via sol gel technique is $1.1902 \mathrm{kG}, 200 \%$ higher than the sample of the same formula prepared via conventional technique. We speculate the better formation of microstructure in samples prepared via sol gel technique gave the higher $\mathrm{B}_{\max }$ value. Substituting $\mathrm{Bi}^{2+}$ to $\mathrm{Y}^{3+}$, as a result increases the net magnetic moment of the garnet system. From Fig. 3 and Table 1, the $\mathrm{B}_{\max }$ for sample $\mathrm{C} 1$ and sample $\mathrm{C} 2$ is $0.3673 \mathrm{kG}$ and $0.4979 \mathrm{kG}$, respectively. This is in accord with the above statement. Sample $\mathrm{S} 1$ gave higher $\mathrm{B}_{\max }(1.1902 \mathrm{kG})$ as compared to sample S2 $(0.8635 \mathrm{kG})$. As mentioned, bismuth is a sintering aid. Too much bismuth content resulted in formation of pores. 
XRD graph of sample $\mathrm{Y}_{2.8} \mathrm{Bi}_{0.2} \mathrm{Fe}_{5} \mathrm{O}_{12}$

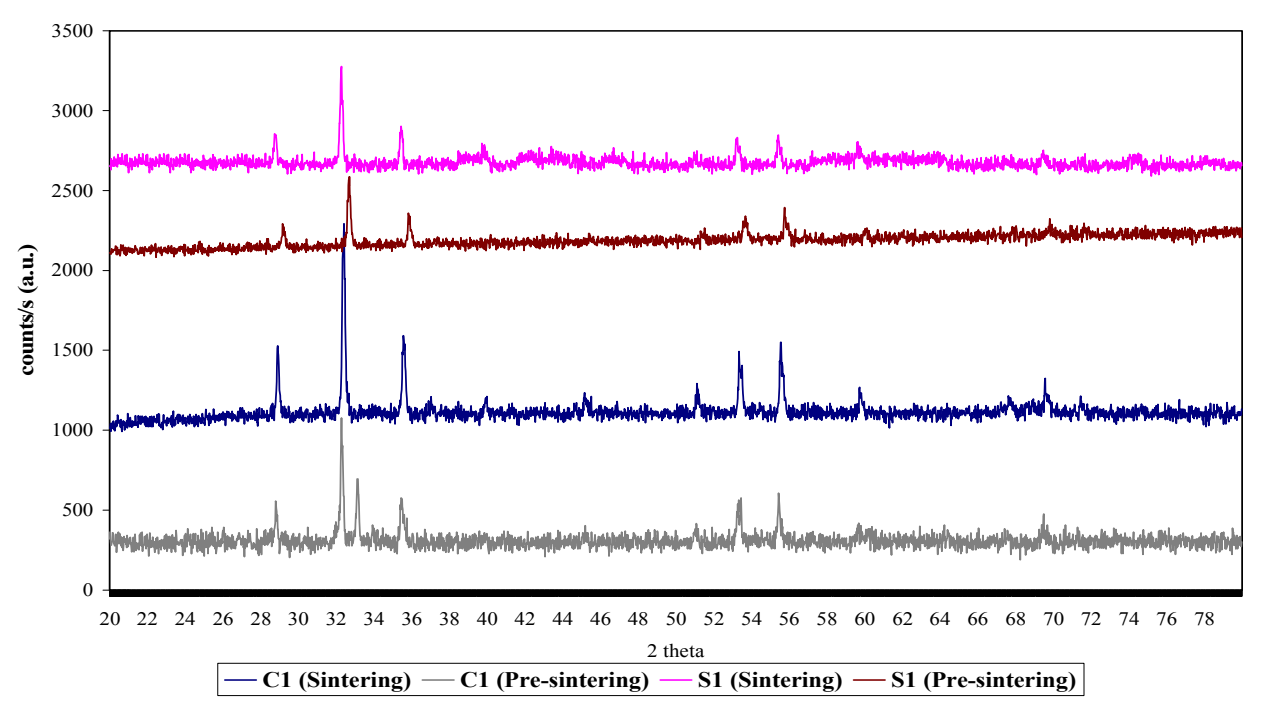

Fig. 1: X-ray diffraction profile for sample $\mathrm{C} 1$ and $\mathrm{S} 1$ for pre-sintering and sintering

Table 1: Results of Density, Shrinkage, Saturation Induction $\left(\mathrm{B}_{\max }\right)$ and Initial Permeability and XRD before and after sintering for samples $\mathrm{C} 1$, $\mathrm{C} 2, \mathrm{~S} 1$ and $\mathrm{S} 2$

\begin{tabular}{lcccc}
\hline \multirow{2}{*}{ Sample } & \multicolumn{2}{c}{ Conventional Technique } & \multicolumn{2}{c}{ Sol-Gel Technique } \\
\cline { 2 - 5 } & \multicolumn{2}{c}{$\mathrm{Y}_{2.8} \mathrm{Bi}_{0.2} \mathrm{Fe}_{5} \mathrm{O}_{12}$} & $\mathrm{Y}_{2.6} \mathrm{Bi}_{0.4} \mathrm{Fe}_{5} \mathrm{O}_{12}$ & \multicolumn{2}{c}{$\mathrm{Y}_{2.8} \mathrm{Bi}_{0.2} \mathrm{Fe}_{5} \mathrm{O}_{12}$} & \multicolumn{2}{c}{$\mathrm{Y}_{2.6} \mathrm{Bi}_{0.4} \mathrm{Fe}_{5} \mathrm{O}_{12}$} \\
$\mathrm{~S}^{2}$ & \multicolumn{2}{c}{$\mathrm{C} 2$} & 4.8493 & 5.1238 \\
\hline Density $\left(\mathrm{g} / \mathrm{cm}^{3}\right)$ & 4.2378 & 4.5262 & 10.9103 & 11.3720 \\
Shrinkage $(\%)$ & 5.3047 & 7.1270 & 1.1902 & 0.8635 \\
$\mathrm{~B}_{\max }(\mathrm{kG})$ & 0.3673 & 0.4979 & 40.0393 & 30.1530 \\
Initial Permeability, $\left(\mu_{\mathrm{i}}^{\prime}\right)$ at $10 \mathrm{MHz}$ & 54.4105 & 38.8799 & 32.2700 & 32.1900 \\
XRD Pre-sintering $(2 \vartheta)$ & 32.2900 & 32.7100 & 32.4100 & 32.1900 \\
XRD Sintering $(2 \theta)$ & 32.4100 & 32.2900 & & \\
\hline
\end{tabular}

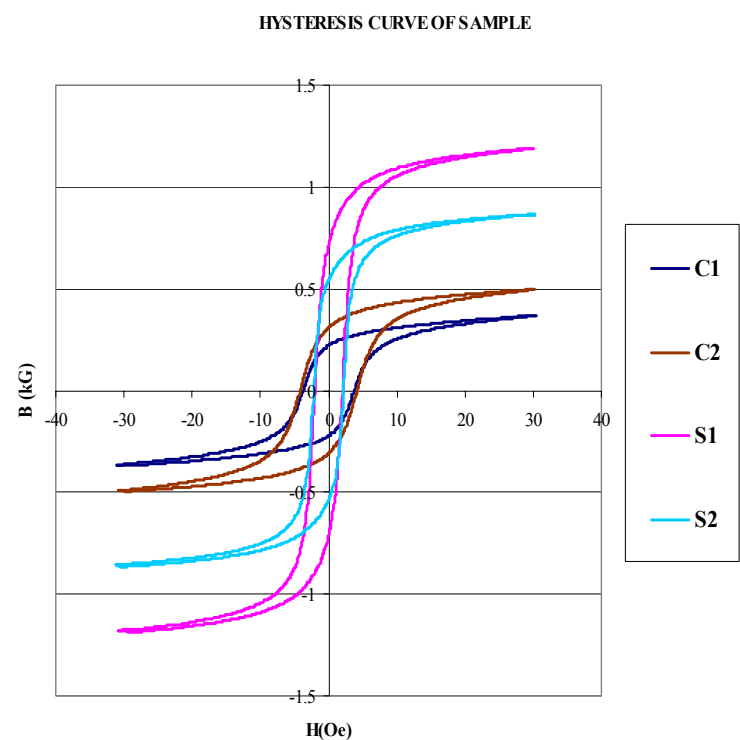

Fig. 2: Hysteresis graphs of samples C1, S1, C2 and S2 measured at room temperature
The microstructure of sample S1 and sample S2 will have a large impact on the magnetic properties. The microstructure of S1 (Fig. 3) is large, almost poreless and homogenous. On the other hand, the microstructure of sample S2 is porous and there are some traces of liquid phase sintering due to the melting of the structures. This had weakened the superexchange interaction and thus reduced the saturation induction, $\mathrm{B}_{\max }$.

Coercive force $\left(\mathrm{H}_{\mathrm{c}}\right)$ is expected to be the most sensitive of all properties, with respect to density ${ }^{[10]}$.

Observing the $\mathrm{H}_{c}$ (Fig. 2), it is notable that both samples that were prepared via sol gel technique gives lower $\mathrm{H}_{\mathrm{c}}$. We attribute this to the speculation made; higher density (Table 1), which is associated with the homogeneous and poreless microstructure (Fig. 3). Comparing the coercive force between the two techniques, it is obvious that samples prepared via conventional method showed higher coercive force. Most likely, smaller grain size gives greater number of grain boundaries. When a moving domain wall 


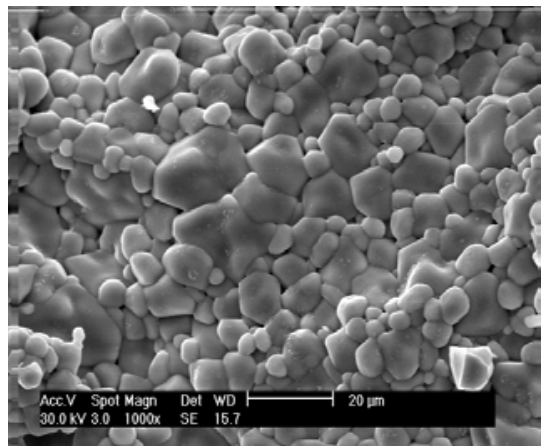

Fig. 3: Scanning electron microscopy image of sample S1 prepared via sol-gel technique

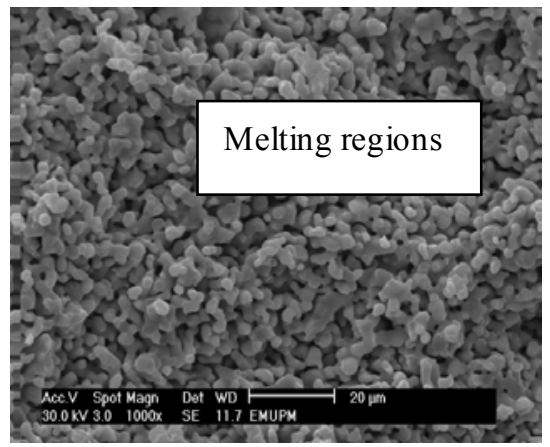

Fig. 4: Scanning electron microscopy image of sample $\mathrm{C} 1$ prepared via solid state technique

INITIAL PERMEABILITY VS FREQUENCY

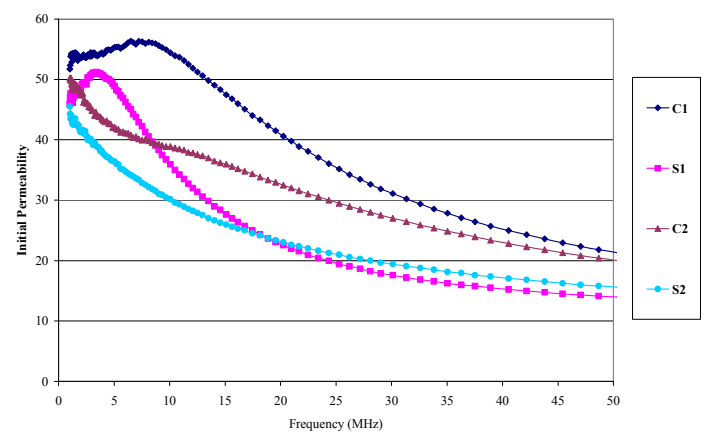

Fig. 5: Initial permeability vs. frequency of samples $\mathrm{C} 1, \mathrm{~S} 1, \mathrm{C} 2$ and $\mathrm{S} 2$ measured at room temperature

encounters a grain boundary, the wall area is reduced and the total energy is lowered in proportion to the wall-surface energy density. As a result, additional energy in the form of an increased applied field is required to overcome the decrease in wall energy and free it from the pore. This resulted in an increase of coercive force. The result obtained in this work is in accord with the general theories of coercivities.

Table 1 gives the initial permeability over at 50 MHz. Samples that were prepared via conventional technique gave higher initial permeability, 54.41 and 38.88 for samples $\mathrm{C} 1$ and $\mathrm{C} 2$ respectively. However, the initial permeability of those prepared via sol gel technique showed slightly lower, 40.04 and 30.15 for samples S1 and S2, respectively (Fig. 5). However, the resonance frequency for the S1 and S2 samples are higher than those prepared conventional technique. Additional of $\mathrm{Bi}^{3+}$ ions would result in increase of unwanted pores as well of melting points, this may be the cause of the lower initial permeability of the samples prepared via both the techniques.

Internal stress, $\sigma$, is another factor that could have affected the initial permeabilty. When internal stress, $\sigma$, decreased, initial permeability, $\mu_{\mathrm{i}}^{\prime}$ would increase. We speculate, less internal stress for samples prepared via conventional technique resulted to the higher permeability.

From the result, there was an increase of initial permeability, $\mu_{\mathrm{i}}^{\prime}$ starting from $1 \mathrm{MHz}$ to $15 \mathrm{MHz}$ for all the samples. A decline in the initial permeability are seen in all the samples at higher frequencies, above 20 MHz. This is due to the non-magnetic effect of the bismuth that had weakened the super-exchange interaction.

\section{CONCLUSION}

Each of the methods presented here enables the production of single phase yttrium iron garnet which have excellent magnetic properties. This study shows that rigorous control of preparation technique gives different magnetic properties, such as $\mathrm{B}_{\max }$ and initial permeability. The density and shrinkage for samples prepared via sol gel technique are higher then those prepared via conventional route. Substituting bismuth to yttrium in the garnet system enhanced the density and shrinkage for both techniques due to it's role as a sintering aid. In conclusion, the sol gel technique appears to be the favourable technique; the 40 and $50 \%$ reduction of sintering temperature and of sintering time, respectively, is an attractive route for the preparation of single phase bi-substituted yttrium iron garnet. This is due to the possible reduction of cost of production and the enhanced magnetic and structural properties of the samples.

\section{ACKNOWLEDGEMENT}

The authors thanks the Ministry of Science, Technology and Innovative for the fund provided under IRPA grant 54430.

\section{REFERENCES}

1. Priye, V., B.P. Pal and K. Thyagarajan, 1998. Analysis and design of a novel leaky YIG film guided wave optical isolators. J. Lightwave Technol., 16: 2. 
2. Sekijima, T., T. Fujii, K. Wakino and M. Okada, 1999. Optical faraday rotator using Ce-substituted fibrous YIG Single crystal grown by floating-zone method with YAG laser heating. IEEE Trans. on Microwave Theory and Techniques, 47: 12.

3. Goldman, A., 1990. Technological Ferrites. Oxford Publications.

4. Standley, K.J.,1972. Oxide Magnetic Materials. 2 Edn. Clarendon Press, Oxford,.

5. Marysko, M., 1994. Anisotropy and FMR in cobalt doped YIG Films. IEEE Trans. on Magnetics, 30: 2 .

6. Zhang, F., Y. Xu, J. Yang and M. Guillot, 2000. A theoretical study of the magnetic and magnetooptical properties of Nd-substituted yttrium iron garnets. J. Phys.: Condens. Matter, 12.
7. Shackelford, J.F., 2000. Introduction to Materials Science for Engineers. University of California, Davis, 5th Edn.

8. Slick, P.I., 1980. Ferrites for non-microwave application. E.P. Wohlfarth, Ferromagnetic Materials, pp: 189-296.

9. Yahya, N. and M. Hashim, 1995. The effect of substituting $\mathrm{Cu}^{2+}$ for $\mathrm{Ni}^{2+}$ utilising the coprecipitation method in NiZn ferrite. Bull. Malaysia Solid State Sci. Technol., 6: 83-98.

10. Tebble, R.S. and D.J. Craik, 1969. Magnetic Materials. Willey-Interscience. 